\section{Re: Marketing Messages in Continuing Medical Education (CME) Modules on Binge- Eating Disorder (BED)}

To the Editor: Jung and Berman ${ }^{1}$ suggested medical education companies were not compliant with The Standards for Commercial Support: Standards to Ensure Independence in CME Activities ${ }^{\mathrm{SM}}$ required by the Accreditation Council for Continuing Medical Education. Medscape, an accredited provider for over 20 years, has strict policies and procedures that prevent commercial influence on our content. We take every accusation suggesting otherwise very seriously and reviewed the 3 Medscape activities mentioned in the article for validity of the claims made by the authors. Here are our findings:

- All 3 Medscape activities were developed free from influence by commercial interests, including the identification of the educational need, selection of faculty, development of learning objectives and content, dissemination, and outcomes evaluation.

- Two of the 3 Medscape activities were independently peer reviewed prior to posting online and the reviewers found the content to be aligned with the learning objectives and free of bias.

- Two of the 3 Medscape activities are largely text based; 1 is a blend of text and video; the slides mentioned in the article are not in our content.

- Across all 3 Medscape activities, all slides were originally created by Medscape and were not supplied by the faculty.

- The claims in the paper about promoting lisdexamfetamine as a safe and effective drug for binge-eating disorder and/or weight loss do not appear in any of our activities. Rather, the lisdexamfetamine is rarely mentioned as our 3 activities were developed prior to availability of phase- 3 data; and when mentioned, it was categorized correctly as a stimulant.

Throughout the article the authors regularly refer to the "CME modules" as a whole and even in their Discussion section state that some of their claims are more conjecture rather than proven. Because of this, we feel strongly that Medscape was guilty by association by having posted content on this topic within the sample time of the study. It is unfortunate the authors had a forum to spread misinformation to propagate their own agenda.

\author{
Kathleen N. Geissel, PharmD \\ Medscape, LLC 825 Eighth Ave, 11th Floor \\ New York, NY 10019 \\ kgeissel@medscape.net
}

To see this article online, please go to: $\mathrm{bttp}: / / j a b f m . o r g / c o n t e n t /$ 33/5/816.full.

\section{Reference}

1. Fugh JJ, Berman A. Marketing messages in continuing medical education (CME) modules on binge-eating disorder (BED). J Am Board Fam Med 2020;33:240-251.

doi: 10.3122/jabfm.2020.05.200189

The above letter was referred to the author of the article in question, who offers the following reply.

\section{Response: Re: Marketing Messages in Continuing Medical Education (CME) Modules on Binge-Eating Disorder (BED)}

To the Editor: No one disputes that drug companies provide educational grants for continuing medical education (CME); as the largest CME provider in the country, Medscape receives substantial funds from industry. In this case, all 3 Medscape activities ${ }^{1-3}$ were funded by Shire.

Medscape's modules on binge-eating disorder (BED) contain many marketing messages, including linking $\mathrm{BED}$ to obesity, and linking lisdexamfetamine with weight loss. Omissions are important, too: not one of Medscape's modules mention that lisdexamfetamine, like other amphetamines, has a high potential for abuse, and other serious harms including stroke and sudden death.

Medscape's CME activities specifically link obesity with BED; stating, for example, "Anyone who presents with weight concerns should be asked about binge eating." 1 The correct answer to 1 test question is "Most people with obesity demonstrate binge-eating behavior." Another test question asked:

"Mary, a 36-year-old woman, comes to your office with complaints of a "sore back." She stands $5 \mathrm{ft} 6$ in tall and weighs $265 \mathrm{lb}$. A radiograph reveals no disc or vertebral problems. You are concerned that her sore back may be due to her weight. Which of the following is the most appropriate treatment approach?" 1,4

The correct answer is, "Ask, in the privacy of the examination room, if she has trouble with binge eating." The far more rational answer, "Emphasize that she is obese and should go on a strict diet and exercise regimen" is deemed incorrect. 
Medscape's statement that its Shire-funded activities cannot be industry influenced because they "were developed before availability of phase 3 data" simply proves our point that CME is used as marketing years before a drug is approved. Before the approval of Vyvanse, a Medscape activity promoted Shire's drug, stating, "Lisdexamfetamine dimestylate, which is approved for the treatment of Attention Deficit Hyperactivity Disorder (ADHD), is being investigated as a potential treatment for BED." Another preapproval activity links lisdexamfetamine with weight loss: "Although a change in weight was not an outcome, it was monitored as a safety variable and weight loss was documented with lisdexamfetamine as opposed to placebo" and implies an advantage over other drugs: "... although selective serotonin reuptake inhibitors (SSRIs) are modestly effective for reducing binge eating, they are usually not associated with clinically significant weight loss."

Despite this endorsement via CME, the label for Vyvanse (approved in 2015 as the first drug for BED), specifically contraindicates its use for weight loss. ${ }^{5}$

After lisdexamfetamine was approved, Medscape released another Shire-funded CME, called Test Your Knowledge of Challenging Cases in Eating Disorders. ${ }^{6}$ It is a perfect example of the use of CME to promote a drug and conduct market research. Shire paid Medscape not only for creating $\mathrm{CME}$ but for analyzing its impact. Market research analyses allow a company to see how effective a program is: Will it increase diagnoses of the targeted condition? Will it increase prescribing of the targeted drug?

Two of the 4 CME questions for this activity recommend lisdexamfetamine. The market research report shows that before taking this CME activity, $40 \%$ of the physicians said they would choose to continue prescribing lisdexamfetamine for BED in a particular patient vignette. When presented with the same situation again at the end of the program, $82 \%$ said they would continue lisdexamfetamine. ${ }^{7}$ A doubling in intent to prescribe is a sizable return on investment.

Leslie Citrome, MD, MPH, served as a faculty member for the CME program ${ }^{6}$ and also coauthored the market research report. ${ }^{7}$ Medscape's use of faculty members for both education and marketing may be inconsistent with Food and Drud Administration's Guidance on Industry Supported Scientific and Educational Activities. ${ }^{8}$

Unfortunately, such use does not violate Accreditation Council for Continuing Medical Education (ACCME) standards. Not only does ACCME allow industry-paid physicians and industry employees to provide CME, but it hides and distorts the amount of money industry spends on CME. ACCME makes no real attempt to exclude commercial bias in the activities they accredit.

The fact that Medscape reviewers found content to be free of bias means nothing. Commercially biased activities are designed not to raise suspicion. Qualitative research techniques can be used to identify bias. My research team has pioneered the reverse engineering of marketing messages in CME; we have documented promotional messages in CME activities on hypoactive sexual desire disorder, ${ }^{10}$ chronic noncancer pain, ${ }^{11}$ and BED. $^{12}$ Our studies - and every other study on marketing messages or changes in prescribing behavior related to industry-funded $\mathrm{CME}^{13-15}$ - have found commercial bias, because, well, it is almost always there.

In short, both the qualitative methods we have pioneered to assess marketing in $\mathrm{CME}$, and the quantitative methods Medscape itself uses, show that CME is a marketing tool for pharmaceutical companies. Industry-funded CME serves industry, not physicians, patients, or society.

Adriane Fugh-Berman, MD Department of Pharmacology and Physiology, Georgetown University Medical Center, Washington, DC ajf29@georgetown.edu Jin Jung, PharmD

To see this article online, please go to: http://jabfm.org/content/ 33/5/817.full.

\section{References}

1. Bulik CM, Keck PE, McElroy SL, Vega CP. Recent advances in the management of binge eating disorder. March 26, 2014. Available from: https://www.medscape. org/viewarticle/821956?src=wnl_cme_revw.

2. McElroy SL. Assessing the impact of binge eating disorder: focus on your practice. December 26, 2013. http:// www.medscape.org/viewarticle/818103.

3. McElroy SL, Vega CP. Improving the management of binge eating disorder: a collaborative treatment approach. September 2, 2014. Available from: http://www.medscape. org/viewarticle/830450_transcript.

4. Spyropoulos J, Chatterjee P, Desai J, Vega C. Effectiveness of online CME in improving knowledge and awareness related to emerging management approaches for binge-eating disorder (poster). Available from: https://img.medscapestatic. $\mathrm{com} / \mathrm{pi} / \mathrm{edu} / \mathrm{qrcode} / \mathrm{posters} /$ effectiveness-of-online-cme-forbinge-eating-disorder.pdf Accessed July 8, 2020.

5. Vyvanse. Available from: https://www.accessdata.fda.gov/ drugsatfda_docs/label/2017/208510lbl.pdf.

6. Citrome L. Test your knowledge of challenging cases in eating disorders. February 23, 2016. Available from: https://www.medscape.org/viewarticle/855587.

7. Lubarda J, Chatterjee P, Citrome L. Binge eating disorder management: can medical education improve physician knowledge? (poster). Available from: https://img. medscapestatic.com/pi/edu/qrcode/posters/binge-eatingdisorder-management-can-medical-education-improvephysician-knowledge.pdf. Accessed July 8, 2020.

8. FDA Guidance document: industry-supported scientific and educational activities. December 1997. Available from: https://www.fda.gov/regulatory-information/search-fdaguidance-documents/industry-supported-scientific-andeducational-activites. Accessed July 10, 2020.

9. Fugh-Berman A, Hogenmiller A. CME stands for commercial medical education: and ACCME still won't address the issue. J Med Ethics 2016;42:172-3.

10. Meixel A, Yanchar E, Fugh-Berman A. Hypoactive sexual desire disorder: inventing a disease to sell low libido. J Med Ethics 2015;41:859-62.

11. Infeld M, Bell A, Marlin C, et al. Continuing medical education and the marketing of fentanyl for breakthrough 
pain: marketing messages in an industry-funded CME module on breakthrough pain. World Med Health Pol 2019;11:43-58

12. Jung J, Fugh-Berman A. Marketing messages in continuing medical education (CME) modules on binge-eating disorder (BED). J Am Board Fam Med 2020;33:240-51.

13. Dieperink ML, Drogemuller L. Industry-sponsored grand rounds and prescribing behavior. JAMA 2001;285:1443-4.

14. Orlowski JP, Wateska L. The effects of pharmaceutical firm enticements on physician prescribing patterns. There's no such thing as a free lunch. Chest 1992;102:270-3.

15. Bowman MA, Pearle DL. Changes in drug prescribing patterns related to commercial company funding of continuing medical education. J Contin Educ Health Prof 1988;8:13-20.

doi: 10.3122/jabfm.2020.05.200189

\section{Re: Addressing Needs of Transgender Patients: The Role of Family Physicians}

To the Editor: The study from Radix ${ }^{1}$ exposes the circumstances faced by transgender individuals when seeking health services, and affirms the need for welcoming health care environments, with health care providers who are knowledgeable about their special needs. It also demonstrates strategies that family doctors can use to improve their clinical practices. The disparity in access to health was very well described in the present study, which showed that the difficulty in accessing care leads to higher rates of problems related to mental health, substance use disorder, violence, and poverty.

Furthermore, Radix et $\mathrm{al}^{1}$ show that heteronormativity is still a form of discrimination present in the health system, and transgender people may be harmed by the difficulty of finding professionals with aptitude to care for their needs. In South Africa, a study from NewmanValentine and Duma ${ }^{2}$ corroborates the findings from Radix, ${ }^{1}$ stating that transgender individuals receiving transition-related treatments may suffer significant side effects, which can be managed successfully by knowledgeable health professionals. In this matter, it is evident that the knowledge derived from experiences in health fields must be shared, so that there will be awareness of procedures related to gender transition, helping in the process of building social intelligibility for these people. Thus, we need to produce scientific knowledge about transgenderism and expected social experiences related to transitioning to educate individual patients and their health professionals, to prepare for a successful transition. ${ }^{3}$

We congratulate Radix ${ }^{1}$ for providing data that reveals the considerable importance humanized care has to transgender individuals, requiring from the professional a general vision of gender and sexuality, to avoid discrimination, and to improve access of this population to primary health care. In addition to basic knowledge of hormonal therapies, appropriate individual HIV risk assessments and appropriate prevention strategies, the study also provides us a foundation to implement such practices more effectively in primary health care in Brazil.

Isadora Ponticelli Mondini University of Southern Santa Catarina (UNISUL), Campus Tubarão, Av. José Acácio Moreira, 787, Dehon, Tubarão, SC, 88704-900 Brazil isadoraponticelli@gmail.com

Emanuelle Nichele Luz

Aline Baggio Oenning Chaiana Esmeraldino Mendes Marcon

To see this article online, please go to: http://jabfm.org/content/ 33/5/818.full.

\section{References}

1. Radix AE. Addressing needs of transgender patients: the role of family physicians. J Am Board Fam Med 2020;33:314-21.

2. Newman-Valentine D, Duma S. Injustice to transsexual women in a hetero-normative healthcare system. Afr J Prim Health Care Fam Med 2014;6:1-5.

3. Oliveira ID, Romanini M. (Re) writing (in) visible scripts: the trajectory of transgender women in public health policies. Saude soc 2020;29:(1). Epub ahead of print.

doi: 10.3122/jabfm.2020.05.200189 